\title{
Changes in the magnitude of social inequality in the uptake of cervical cancer screening in Taiwan, a country implementing a population-based organized screening program
}

Shu-Ti Chiou ${ }^{1,2}$, Chien-Yuan Wu' ${ }^{1}$ Baai-Shyun Hurng ${ }^{1}$ and Tsung-Hsueh Lu $^{3^{*}}$

\begin{abstract}
Introduction: We sought to examine changes in the magnitude of social inequality in the uptake of cervical cancer screening between 2001 and 2009 in Taiwan.

Methods: We used data from the 2001 and 2009 Taiwan National Health Interview Surveys to calculate the absolute (slope of index of inequality, SII) and relative (relative index of inequality, RII) summary measures of social inequality in the uptake of Pap smear tests to indicate the magnitude of social inequality.

Results: The prevalence of having had a Pap smear during the previous 3 years increased in each age and socioeconomic group from 2001 to 2009. The SII and RII by urbanization and education level decreased significantly, while the SII and RII by income level increased significantly between the two study years. The largest increase in inequality of prevalence from 2001 to 2009 was between women living in suburban and rural areas with highest income level and women live in metropolitan areas with lowest income level.
\end{abstract}

Conclusions: The changes in magnitude of social inequality in the uptake of cervical cancer screening differed by indicators of socioeconomic position. Further studies are needed to explore the mechanisms that result in social inequality by different indicators of socioeconomic position.

Keywords: Mass screening, National Health Interview Survey, Socio-economic factors, Uterine cervical neoplasm

\section{Introduction}

Studies using nationally-representative survey data have demonstrated prominent social inequality in the reported use of cervical cancer screening [1-13]. In most countries, women in a higher socioeconomic position have higher rates of Pap smear test uptake than their counterparts in a lower socioeconomic position. However, according to a review, very few studies directly compare the trends in socioeconomic inequality in the uptake of cervical cancer screening [14]. An international comparison study further indicated that the magnitude of social inequality in the prevalence of the uptake of cervical cancer screening is lower in countries implementing a population-based organized screening

\footnotetext{
* Correspondence: robertlu@mail.ncku.edu.tw

${ }^{3}$ Institute of Public Health, National Cheng Kung University, Tainan, Taiwan Full list of author information is available at the end of the article
}

program [11]. Nevertheless, little is known regarding the changes in the magnitude of social inequality in a country implementing population-based organized screening program in an Asian country. In this study, we examine changes in the magnitude of social inequality in the reported uptake of cervical cancer screening between 2001 and 2009 in Taiwan, a country that has been implementing population-based organized screening program since 1995.

\section{Methods \\ Organized screening program in Taiwan \\ According to the definition proposed by Miles et al., the cervical screening program in Taiwan is an organized system [15]. The National Cervical Cancer Screening Registry was established in 1995 to help public health nurses to identify women who should be invited for a}


Pap smear and to monitor whether any screening-detected abnormalities have been followed-up and treated [16,17]. However, one limitation of the National Cervical Cancer Screening Registry is that there is no personal information on socioeconomic position; therefore we have to use the National Health Interview Survey datasets to examine the relationship between socioeconomic position and prevalence of Pap smear usage.

\section{National Health Interview Survey in Taiwan}

The National Health Interview Survey is a nationallyrepresentative survey of the total population of Taiwan conducted by the Bureau of Health Promotion every four years. A multistage stratified systematic sampling design following the principle of probability proportional to size was applied in both the 2001 and 2009 surveys. Data were collected by face-to-face interview [18]. The response rate was $93.8 \%(25,464 / 27,160)$ in the 2001 survey and $84.0 \%(25,636 / 30,528)$ in the 2009 survey. One possible explanation of the difference in response rate between 2001 and 2009 is that the unit of sampling in 2001 was by household and in 2009 it was by individual person.

\section{Variables}

The dependent variable was having had a Pap smear during the previous 3 years, which was determined by the question: "In what year and month did you have a Pap smear, if ever?" The independent variables included age and three indicators of the respondent's socioeconomic position: residential urbanization level, educational level, and monthly household income. The definitions of variables are illustrated in Table 1.

\section{Analysis}

The prevalence of having had a Pap smear in the previous 3 years was calculated by age and three indicators of socioeconomic position. We then examined the correlations (Cramer's V coefficient) among variables, and used the variation inflation factor (VIF) to address the concern of colinearity between covariates. The adjusted odds ratio (aOR) of having had a Pap smear in the previous 3 years for women in each socioeconomic group compared with women in a reference group was computed according to multivariate logistic regression. We also examined the interactions between different independent variables in predicting the outcome. For variables with significant interaction effects, we further stratified the variables and computed the aOR for stratified categories.

\section{Measure of inequality}

Because we used indicators of socioeconomic position with hierarchical order (urbanization, education and
Table 1 Definitions of variables

\begin{tabular}{|c|c|}
\hline Variable & Definition \\
\hline \multicolumn{2}{|l|}{ Dependent variable } \\
\hline \multirow[t]{2}{*}{ Pap smear } & $\begin{array}{l}\text { If the respondent received Pap } \\
\text { smear in the previous } 3 \text { years; }\end{array}$ \\
\hline & yes $=1$, otherwise $=0$ \\
\hline \multicolumn{2}{|l|}{ Independent variables } \\
\hline \multicolumn{2}{|l|}{ Age } \\
\hline $30-39$ & $\begin{array}{l}\text { If the respondent's age is in } 30-39 \text { years; } \\
\text { yes }=1 \text {, otherwise }=0 \text { (reference group) }\end{array}$ \\
\hline $40-49$ & $\begin{array}{l}\text { If the respondent's age is in } 40-49 \text { years; } \\
\text { yes }=1 \text {, otherwise }=0\end{array}$ \\
\hline $50-59$ & $\begin{array}{l}\text { If the respondent's age is in } 50-59 \text { years; } \\
\text { yes }=1 \text {, otherwise }=0\end{array}$ \\
\hline $60-69$ & $\begin{array}{l}\text { If the respondent's age is in } 60-89 \text { years; } \\
\text { yes }=1 \text {, otherwise }=0\end{array}$ \\
\hline \multicolumn{2}{|l|}{ Urbanization level } \\
\hline Metropolitan & $\begin{array}{l}\text { If the respondent's resident place is in } \\
\text { Taipei City or Kaohsiung City; yes }=1 \text {, } \\
\text { otherwise }=0 \text { (reference group) }\end{array}$ \\
\hline Urban & $\begin{array}{l}\text { If the respondent's resident place is in } \\
\text { Cities other than Taipei City or Kaohsiung } \\
\text { City; yes }=1 \text {, otherwise }=0\end{array}$ \\
\hline Suburban & $\begin{array}{l}\text { If the respondent's resident place is in } \\
\text { "Zhen" (township); yes }=1 \text {, otherwise }=0\end{array}$ \\
\hline Rural & $\begin{array}{l}\text { If the respondent's resident place is in } \\
\text { "Xiang" (village); yes }=1 \text {, otherwise }=0\end{array}$ \\
\hline \multicolumn{2}{|l|}{ Educational level } \\
\hline Primary or lower & $\begin{array}{l}\text { If the respondent's highest education } \\
\text { level is primary school or lower; yes = 1, } \\
\text { otherwise }=0 \text { (reference group) }\end{array}$ \\
\hline Secondary & $\begin{array}{l}\text { If the respondent's highest education level } \\
\text { is junior high school; yes }=1 \text {, otherwise }=0\end{array}$ \\
\hline High school & $\begin{array}{l}\text { If the respondent's highest education level } \\
\text { is senior high school; yes }=1 \text {, otherwise }=0\end{array}$ \\
\hline College or university & $\begin{array}{l}\text { If the respondent's highest education level } \\
\text { is college or university; yes }=1 \text {, otherwise }=0\end{array}$ \\
\hline Graduate school & $\begin{array}{l}\text { If the respondent's highest education level } \\
\text { is graduate school; yes }=1 \text {, otherwise }=0\end{array}$ \\
\hline \multicolumn{2}{|c|}{ Household monthly income (NT dollars) } \\
\hline$\leq 29,999$ & $\begin{array}{l}\text { If the respondent's reported income is } \leq 29,999 \text {; } \\
\text { yes }=1 \text {, otherwise }=0 \text { (reference group) }\end{array}$ \\
\hline $30,000-49,999$ & $\begin{array}{l}\text { If the respondent's reported income is } \\
30,000-49,999 ; \text { yes }=1 \text {, otherwise }=0\end{array}$ \\
\hline $50,000-69,999$ & $\begin{array}{l}\text { If the respondent's reported income is } \\
50,000-69,999 ; \text { yes }=1 \text {, otherwise }=0\end{array}$ \\
\hline 70,000-99,999 & $\begin{array}{l}\text { If the respondent's reported income is } \\
70,000-99,999 ; \text { yes }=1 \text {, otherwise }=0\end{array}$ \\
\hline$\geq 100,000$ & $\begin{array}{l}\text { If the respondent's reported income is } \\
\geq 100,000 ; \text { yes }=1 \text {, otherwise }=0\end{array}$ \\
\hline
\end{tabular}

income level), we were able to use regression-based measures of social inequality [19]. The slope index of inequality (SII) is the linear regression coefficient which represents the relation between the frequencies of health behavior (i.e., undertaking a Pap smear in this study) in each socioeconomic category and the hierarchical 
ranking of each category on the social scale [20]. The SII can be interpreted as the absolute change in frequency of health behavior when one goes from the lowest level in the social hierarchy to the highest level.

Because SII is an absolute measure, it is sensitive to changes in the mean frequency of health behaviors of population. If the mean frequency of health behavior increases in the same proportion in all the socioeconomic categories, the SII will increase, whereas the relative differences remain constant. One alterative that has been proposed is the relative index of inequality (RII), which can be estimated by dividing the predicted value of the regression at the highest point by the predicted value of the regression at the next highest point. The RII is frequently calculated by logistic regression at the lowest point. After the logistic transformation of the dependent variable, the exponent of the regression coefficient represents the RII [20].

Here is a simple example to help readers better understand the implication of SII and RII. Suppose the prevalence of taking Pap smear for low, middle, and high socioeconomic positions were $60 \%, 65 \%$ and $70 \%$, respectively. In this example, there was a $5 \%$ point of increase in prevalence from low socioeconomic position to the adjacent higher socioeconomic position, the SII would be around $0.08(5 / 60)$ and the RII would be around $1.08(65 / 60$ or $70 / 65)$.

As the main concern of this study was to examine changes in the magnitude of social inequality between 2001 and 2009, we pooled data from both years and included an interaction term between SII, RII, aOR and survey year in the model.

As Martens pointed out, the use of relative rates, relative risks, or odds ratios can actually be detrimental to furthering political actions. In the realm of policy, showing the rates by socioeconomic group on absolute differences may be better understood intuitively [21]. Thus, we presented changes in both rate ratio and rate difference between 2001 and 2009 by three indicators socioeconomic position to see if there were different implications for policy decision makers.

\section{Results}

Women aged 30-69 years who had not had a hysterectomy were included in this study, with a total of 5,704 women for the year 2001 and 6,420 women in 2009. Table 2 presents the demographic and socioeconomic characteristics of the respondents. A higher percentage of women aged 50-59 years was noted in 2009 compared with those in 2001 ( $25 \%$ vs. $19 \%)$. The distributions of respondents by urbanization level and household income in 2001 were similar to those in 2009. However, fewer respondents reported monthly income in 2009. We also found that the 2009 respondents had higher education levels.
The overall prevalence of undertaking a Pap smear was $62 \%$ in 2001 and increased to $69 \%$ in 2009 (Table 3). The increase in prevalence was different between age group and was more prominent for elder woman; thus in the groups of 50-59 and 60-69 year-olds, the increase between years was by $10 \%$. The increase of prevalence between 2001 and 2009 was less prominent in women living in metropolitan areas (an increase from 63\% to $67 \%$ ), compared with those in suburban areas (an increase from $63 \%$ to $71 \%$ ), and rural areas (from $63 \%$ to $72 \%)$. Similarly, women with highest education level and highest household income group showed lowest magnitude of increase in prevalence between the two years (from $66 \%$ to $69 \%$ for the highest education level and from $68 \%$ to $75 \%$ for the highest income group). Noteworthy women with university or graduate education level had lower prevalence rate (69\% in 2009) than those with high school education level (73\%).

Table 4 shows correlation matrix among variables in 2001 and 2009. Although the four independent variables were significantly correlated with each other, the VIF for all variables are less than 2 , so the threat of colinearity between variables was not so significant (data not shown). We therefore put all variables into the final multivariate logistic regression model. A significant interaction term between urbanization and income were noted, we thus stratified urbanization and income into five categories in the final multivariate regression model.

The results of final multivariate logistic regression model are presented in Table 5. The SII and RII by age moderately increased from 2001 to 2009, and the main increase occurred in women aged 50 years and above. The SII and RII by urbanization level were, respectively, 0.18 (95\% CI $0.01-0.27$ ) and 1.20 (95\% CI 1.10-1.31) in 2001 , and significantly decreased to 0.13 (95\% CI 0.04 0.21 ) and 1.14 (95\% CI 1.04-1.24) in 2009 according to the examination of interaction term between urbanization and year. People living in rural areas showed the most prominent decrease in magnitude of inequality, as shown by the aOR which was 1.87 (95\% CI 1.38-2.54) in 2001 and decreased to 1.33 (95\% CI 1.02-1.74).

With regard to education level, SII and RII were, respectively, 0.14 (95\% CI $0.07-0.21$ ) and 1.15 (95\% CI $1.08-1.23)$ in 2001; and significantly decreased to $<0.001$ (95\% CI $-0.07-0.08)$ and 1.00 (95\% CI $0.93-1.08)$ in 2009. The magnitude of decrease in aOR was most prominent among women with a secondary educational level (from 1.63 to 1.23) and women with a high school education level (from 1.68 to 1.32 ).

In terms of household monthly income, the SII and RII were, respectively, 0.15 (95\% CI 0.09-0.22) and 1.16 (95\% CI 1.09-1.24) in 2001. These significantly increased to 0.21 (95\% CI -0.14-0.28) and 1.24 (95\% CI 1.16-1.32) in 2009. The increase in inequality was mainly confined 
Table 2 Demographic and socioeconomic characteristics of women respondents, 2001 and 2009 Taiwan National Interview Survey

\begin{tabular}{|c|c|c|c|c|}
\hline & \multicolumn{2}{|c|}{2001} & \multicolumn{2}{|c|}{2009} \\
\hline & $N$ & $\%$ & $N$ & $\%$ \\
\hline Total & 5,704 & 100.0 & 6,420 & 100.0 \\
\hline \multicolumn{5}{|l|}{ Age group (years) } \\
\hline $30-39$ & 1,930 & 33.8 & 2,035 & 31.7 \\
\hline $40-49$ & 1,819 & 31.9 & 1,911 & 29.8 \\
\hline $50-59$ & 1,107 & 19.4 & 1,585 & 24.7 \\
\hline $60-69$ & 848 & 14.9 & 889 & 13.8 \\
\hline Missing & - & - & - & - \\
\hline \multicolumn{5}{|l|}{ Urbanization level } \\
\hline Metropolitan & 1,540 & 27.0 & 2,032 & 31.7 \\
\hline Urban & 1,446 & 25.4 & 1,635 & 25.5 \\
\hline Suburban & 992 & 17.4 & 1,130 & 17.6 \\
\hline Rural & 1,642 & 28.8 & 1,619 & 25.2 \\
\hline Missing & 84 & 1.5 & 4 & 0.1 \\
\hline \multicolumn{5}{|l|}{ Educational level } \\
\hline Primary or lower & 2,393 & 42.0 & 1,681 & 26.2 \\
\hline Secondary & 909 & 15.9 & 945 & 14.7 \\
\hline High school & 1,523 & 26.7 & 2,069 & 32.2 \\
\hline College or university & 816 & 14.3 & 1,492 & 23.2 \\
\hline Graduate school & 60 & 1.1 & 225 & 3.5 \\
\hline Missing & 3 & 0.1 & 8 & 0.1 \\
\hline \multicolumn{5}{|c|}{ Household monthly income (NT dollars) } \\
\hline$\leq 29,999$ & $1,2371,237$ & 21.7 & 1,494 & 23.3 \\
\hline $30,000-49,999$ & $1,3111,311$ & 23.0 & 1,366 & 21.3 \\
\hline $50,000-69,999$ & $1,1901,190$ & 20.9 & 1,035 & 16.1 \\
\hline 70,000-99,999 & 988988 & 17.3 & 828 & 12.9 \\
\hline$\geq 100,000$ & 907907 & 15.9 & 859 & 13.4 \\
\hline Missing & 7171 & 1.2 & 838 & 13.1 \\
\hline
\end{tabular}

to people with monthly income of 70,000-99,999. The aOR of this group was 1.65 in 2001 and increased 2.06 in 2009. Stratified analysis further suggested that the inequality in prevalence between women who live in suburban and rural areas with highest income level compared with women live in metropolitan areas with lowest income level showed the most significant increase in inequality between years: the aOR was 0.31 (95\% CI $0.20-0.50)$ in 2001 and increased to 1.03 (95\% CI 0.64 $1.65)$ in 2009.

Figure 1 illustrates changes in both rate ratio and rate difference in the uptake of Pap smear tests by the three socioeconomic variables. The pattern of change according to rate ratio and rate difference was similar.

\section{Discussion}

The findings of this study suggest that the overall prevalence of cervical cancer screening uptake increased from 2001 to 2009. However, we observed mixed results regarding the changes in relationship between socioeconomic position and the uptake of Pap smear tests. While the magnitude of social inequality by urbanization and education level decreased, the magnitude of social inequality by income level increased. Specifically, the greatest increase of inequality between 2001 and 2009 in screening prevalence occurred between women living in suburban and rural areas with highest income level and women living in metropolitan areas with lowest income level.

A review study that examined the impact of interventions to improve attendance in female cancer screening among lower socioeconomic groups concluded that while organized population screening programs are successful in increasing overall participation rates, they may not necessarily be able to substantially reduce social inequalities [14]. We found the following two studies that specifically examined changes in the magnitude of social inequality in the uptake of cancer screening practices conducted since the publication of that review [22,23]. 
Table 3 Number and prevalence (\%) of women who underwent a Pap smear in the previous 3 years by age and socioeconomic position, 2001 and 2009 Taiwan National Interview Survey

\begin{tabular}{|c|c|c|c|c|c|}
\hline & \multicolumn{2}{|c|}{2001} & \multicolumn{2}{|c|}{2009} & \multirow[t]{2}{*}{$p$-value } \\
\hline & $n$ & $\overline{\%}$ & $n$ & $\%$ & \\
\hline Total & 3,469 & 62.4 & 4,415 & 69.2 & $<.0001$ \\
\hline \multicolumn{6}{|l|}{ Age group (years) } \\
\hline $30-39$ & 1155 & 63.8 & 1387 & 68.4 & 0.0027 \\
\hline $40-49$ & 1241 & 68.8 & 1404 & 73.8 & 0.0008 \\
\hline $50-59$ & 666 & 60.5 & 1114 & 70.9 & $<.0001$ \\
\hline $60-69$ & 407 & 48.4 & 510 & 58.3 & $<.0001$ \\
\hline \multicolumn{6}{|l|}{ Urbanization level } \\
\hline Metropolitan & 953 & 63.1 & 1353 & 67.1 & 0.0118 \\
\hline Urban & 853 & 60.8 & 1109 & 68.1 & $<.0001$ \\
\hline Suburban & 608 & 63.0 & 800 & 71.3 & $<.0001$ \\
\hline Rural & 1000 & 62.8 & 1150 & 71.5 & $<.0001$ \\
\hline \multicolumn{6}{|l|}{ Education level } \\
\hline Primary or lower & 1315 & 55.5 & 1051 & 63.4 & $<.0001$ \\
\hline Secondary & 600 & 67.4 & 669 & 71.2 & 0.0817 \\
\hline High school & 1008 & 68.8 & 1508 & 73.2 & 0.0047 \\
\hline College or university & 545 & 66.0 & 1184 & 69.2 & 0.1030 \\
\hline \multicolumn{6}{|c|}{ Household monthly income (NT dollars) } \\
\hline$<=29,999$ & 676 & 56.0 & 936 & 63.5 & $<.0001$ \\
\hline $30,000-49,999$ & 796 & 62.2 & 933 & 68.5 & 0.0007 \\
\hline $50,000-69,999$ & 750 & 64.8 & 751 & 72.9 & $<.0001$ \\
\hline $70,000-99,999$ & 607 & 63.4 & 656 & 79.3 & $<.0001$ \\
\hline$>=100,000$ & 601 & 68.1 & 647 & 75.4 & 0.0007 \\
\hline
\end{tabular}

An organized breast cancer screening program was implemented in 2001 in Belgium. The prevalence of mammography use in women aged 50-69 years increased from 2001 to 2004; however, the RII by education level also increased [22]. In Korea, the magnitude of social inequality by education level in undertaking gastric cancer screening decreased from 2005 to 2009, but the magnitude of social inequality by income increased [23].

Our findings in Taiwan are similar to those in Korea: we found a decrease in magnitude of social inequality by education level and an increase in magnitude of social inequality by income level. The most often cited

Table 4 Correlations (Cramer's V Coefficient) among variables related to the uptake of Pap smear in Taiwan National Interview Survey

\begin{tabular}{|c|c|c|c|c|c|}
\hline & Uptake_2001 & Age_2001 & Urbanization_2001 & Education_2001 & Income_2001 \\
\hline Uptake_2001 & - & $0.1378^{* * *}$ & 0.0199 & $0.1264^{* * *}$ & $0.0817^{* * *}$ \\
\hline Age_2001 & & - & $0.0551^{* * *}$ & $0.3430^{* * *}$ & $0.1146^{* * *}$ \\
\hline Urbanization_2001 & & & - & $0.1761^{* * *}$ & $0.1270^{* * * *}$ \\
\hline Education_2001 & & & & - & $0.2052^{* * *}$ \\
\hline Income_2001 & & & & & - \\
\hline & & Age_2009 & Urbanization_2009 & Education_2009 & Income_2009 \\
\hline Uptake_2009 & - & $0.1052^{* * *}$ & $0.0420^{*}$ & $0.0821^{* * *}$ & $0.1214^{* * *}$ \\
\hline Age_2009 & & - & $0.0391^{* *}$ & $0.3841^{* * *}$ & $0.1703^{* * *}$ \\
\hline Urbanization_2009 & & & - & $0.1203^{* * *}$ & $0.1121^{* * *}$ \\
\hline Education_2009 & & & & - & $0.3061^{* * *}$ \\
\hline Income_2009 & & & & & - \\
\hline
\end{tabular}


Table 5 Adjusted odds ratios (aOR), relative index of inequality (RII) and slope index of inequality (SII) of having had a Pap smear in the previous three years by age and socioeconomic position, 2001 and 2009 Taiwan National Health Interview Survey

\begin{tabular}{|c|c|c|c|c|c|}
\hline & \multicolumn{2}{|l|}{2001} & \multicolumn{2}{|l|}{2009} & \multirow{2}{*}{$\begin{array}{l}p \text { value for } \\
\text { interactions } \\
\text { with years }\end{array}$} \\
\hline & $\mathrm{aOR}$ & $95 \% \mathrm{Cl}$ & $\mathrm{aOR}$ & $95 \% \mathrm{Cl}$ & \\
\hline \multicolumn{6}{|l|}{ Age group (years) } \\
\hline 30-39 & 1.00 & & 1.00 & & \\
\hline $40-49$ & 1.46 & $(1.26-1.70)$ & 1.33 & $(1.14-1.55)$ & $<.0001$ \\
\hline $50-59$ & 1.15 & $(0.95-1.38)$ & 1.32 & $(1.10-1.59)$ & 0.1413 \\
\hline $60-69$ & 0.79 & $(0.64-0.97)$ & 0.83 & $(0.66-1.05)$ & 0.0272 \\
\hline SII & -0.08 & $(-0.14--0.01)$ & 0.01 & $(-0.07-0.08)$ & 0.0257 \\
\hline RII & 0.93 & $(0.87-0.99)$ & 1.01 & $(0.94-1.08)$ & 0.0257 \\
\hline \multicolumn{6}{|l|}{ Urbanization level } \\
\hline Metropolitan & 1.00 & & 1.00 & & \\
\hline Urban & 1.23 & $(0.84-1.79)$ & 0.71 & $(0.52-0.98)$ & 0.3422 \\
\hline Suburban & 1.75 & $(1.27-2.42)$ & 1.20 & $(0.91-1.59)$ & 0.0185 \\
\hline Rural & 1.87 & $(1.38-2.54)$ & 1.33 & $(1.02-1.74)$ & 0.0015 \\
\hline SII & 0.18 & $(0.10-0.27)$ & 0.13 & $(0.04-0.21)$ & 0.0001 \\
\hline RII & 1.20 & $(1.10-1.31)$ & 1.14 & $(1.04-1.24)$ & 0.0001 \\
\hline \multicolumn{6}{|l|}{ Education level } \\
\hline Primary or lower & 1.00 & & 1.00 & & \\
\hline Secondary & 1.63 & $(1.36-1.96)$ & 1.23 & $(0.99-1.51)$ & $<.0001$ \\
\hline High school & 1.68 & $(1.41-1.99)$ & 1.32 & $(1.09-1.61)$ & $<.0001$ \\
\hline College or university & 1.38 & $(1.12-1.70)$ & 1.00 & $(0.80-1.25)$ & 0.0012 \\
\hline SII & 0.14 & $(0.07-0.21)$ & 0.00 & $(-0.07-0.08)$ & $<.0001$ \\
\hline RII & 1.15 & $(1.08-1.23)$ & 1.00 & $(0.93-1.08)$ & $<.0001$ \\
\hline \multicolumn{6}{|c|}{ Household monthly income (NT dollars) } \\
\hline$<=29,999$ & 1.00 & & 1.00 & & \\
\hline $30,000-49,999$ & 1.57 & $(1.16-2.13)$ & 1.08 & $(0.83-1.42)$ & 0.0659 \\
\hline $50,000-69,999$ & 1.71 & $(1.25-2.32)$ & 1.34 & $(1.01-1.79)$ & 0.0130 \\
\hline $70,000-99,999$ & 1.65 & $(1.21-2.26)$ & 2.06 & $(1.52-2.79)$ & 0.0333 \\
\hline$>=100,000$ & 3.06 & $(2.10-4.45)$ & 1.80 & $(1.29-2.52)$ & $<.0001$ \\
\hline SII & 0.15 & $(0.09-0.22)$ & 0.21 & $(0.14-0.28)$ & $<.0001$ \\
\hline RII & 1.16 & $(1.09-1.24)$ & 1.24 & $(1.16-1.32)$ & $<.0001$ \\
\hline \multicolumn{6}{|l|}{ Urbanization*Income } \\
\hline Metropolitan, <=29,999 & 1.00 & & 1.00 & & \\
\hline Urban, 30,000-99,999 & 0.78 & $(0.51-1.19)$ & 1.53 & $(1.05-2.23)$ & 0.3309 \\
\hline Urban, $>=100,000$ & 0.55 & $(0.32-0.94)$ & 1.32 & $(0.82-2.14)$ & 0.5982 \\
\hline Suburban \& rural, 30,000-99,999 & 0.68 & $(0.48-0.96)$ & 1.03 & $(0.75-1.42)$ & 0.2475 \\
\hline Suburban \& rural, $>=100,000$ & 0.31 & $(0.20-0.50)$ & 1.03 & $(0.64-1.65)$ & 0.0005 \\
\hline
\end{tabular}

Urbanization*study year means interaction term.

hypothesis is the "inverse equity hypothesis" proposed by Victora, which suggests that effective new interventions will initially reach those of a higher socioeconomic position and will only later filter down to those of poorer status [24]. Inequalities in coverage, morbidity, and mortality therefore increase first and then reduced later after lower socioeconomic class have goo access to the intervention. If this hypothesis applies for cervical cancer screenings in Taiwan between the years of 2001 and 2009 , it implies that the availability of screening is still limited to those with greater incomes. Yet this inequality is not likely due to financial barriers because the Bureau of Health Promotion covers the fee for Pap smear examination in all medical settings under the National Health Insurance scheme (which has been in place since 1995). The findings of this study also suggest that there were 

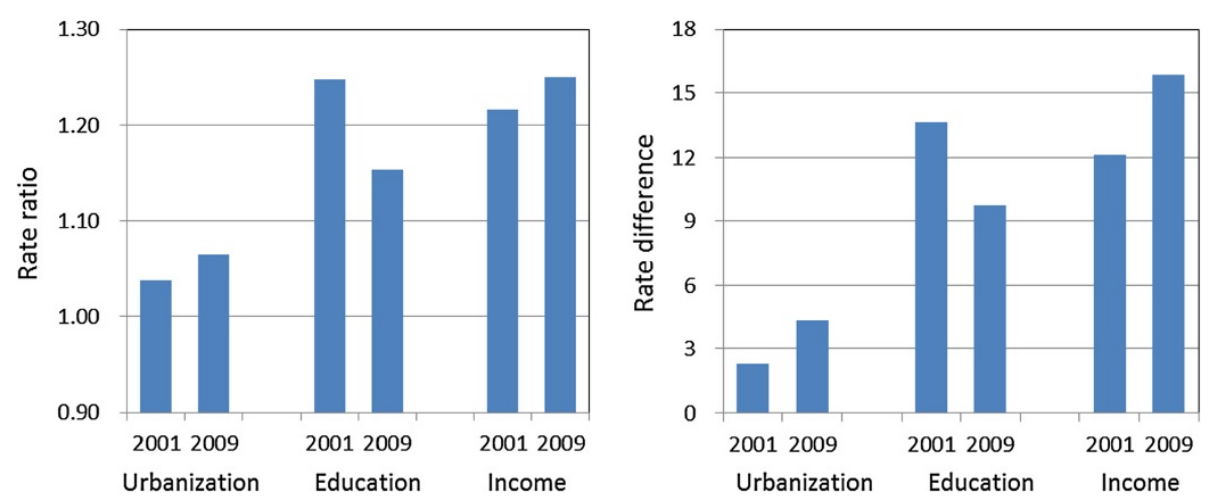

Figure 1 Changes in magnitude of social inequality (rate ratio versus rate difference) in the uptake of Pap smear between 2001 and 2009 according to Taiwan National Health Interview Survey.

interaction effects between urbanization and income level. Further studies are needed to explore the possible mechanisms resulting in the increase in magnitude of social inequality by income level.

The findings of this study further suggest that different indicators of socioeconomic position show alternate pictures of changes in magnitude of social inequality. The magnitude of social inequality as shown by urbanization level in both study years was smaller than those based on education and income level differences. One possible explanation was the launch of outreach communitybased multiple disease screening program in many rural areas in some cities/counties, which resulted in the increase of prevalence cervical cancer screening [25]. The multiple disease screening program used the Pap smear screening program as a base to integrate other screening regimens encompassing four other neoplastic diseases (liver, breast, colon and oral cancer) and three chronic diseases (hypertension, hyperlipidemia, hyperglycemia). The physicians and public health nurses would outreach to many rural areas in which the screening rates were relatively low.

The decrease in magnitude of social inequality by education level was mainly due to the prominent increase in prevalence of the uptake of cervical cancer screening among women with primary or lower education level. This, again, may have been due to the launch of community-based, multiple disease screening outreach program in many rural areas. One evaluation study indicated that the outreach programs are most beneficial to elderly, widowed and less-educated women in rural areas [26]. This would also help explain why there was such a large increase of prevalence of screening in the older populations between years as well. As the demographic characteristics of respondents in 2009 were older and with higher education level than those in 2001, which would be one possible explanation of decrease in the magnitude of social inequality by educational level, as women with the highest education level have lower prevalence rate. The multiple disease screening program is a kind of intervention targeting socioeconomic disadvantages, which could effectively tackle the social inequality in health [27].

Several limitations are worthy of note. First, similar to other studies using National Health Interview Survey datasets, that there might be some recall bias in the selfreporting of the uptake of Pap smear screening. However, as the main objective of this study was to compare the social inequality in the uptake of Pap smear between 2001 and 2009, it is very unlikely that the recall bias changed markedly between the two study years. Another limitation was we could not obtain three waves of data for comparison (the interim 2005 National Health Interview Survey cervical cancer screening questions were not comparable). The third limitation was the higher non-respondent rate and missing rate in providing income information in 2009 wave, which would affect the interpretations of the results.

\section{Conclusion}

We conclude that despite the increase in the prevalence of the uptake of cervical cancer screening between 2001 and 2009, the changes in magnitude of social inequality in the uptake of cervical cancer screening differed by indicators of socioeconomic position. Further studies are needed to explore the different mechanisms resulting in social inequality by different indicator of socioeconomic position.

\section{Competing interests}

All authors declared no competing interests.

\section{Authors' contributions}

STC initiated the idea and supervised the process of study. STC and THL participated in the study design and literature review. All authors participated in the interpretation of the results and critically review the manuscript. All authors read and approved the final manuscript. 


\section{Acknowledgements}

This study is based on data from the National Health Interview Survey provided by the Bureau of Health Promotion, Department of Health, Executive Yuan. The interpretation and conclusions contained herein do not represent those of Bureau of Health Promotion, Department of Health, Executive Yuan. We thank Shi-Liang Wu, Chi-Shiang Chung and Ye-Hsun Wu for help in data analysis.

\section{Funding}

The authors received no financial support for the research, authorship, and/or publication of this article.

\section{Author details}

${ }^{1}$ Health Promotion Administration, Ministry of Health and Welfare, Taipei, Taiwan. ${ }^{2}$ Institute of Public Health, National Yang-Ming University, Taipei, Taiwan. Institute of Public Health, National Cheng Kung University, Tainan, Taiwan.

Received: 10 June 2013 Accepted: 17 December 2013 Published: 9 January 2014

\section{References}

1. Rohlfs I, Borrell C, Pasarín MI, Plaséncia A: The role of sociodemographic factors in preventive practices: the case of cervical and breast cancer. Eur J Public Health 1999, 9:278-284.

2. Sambamoorthi U, McAlpine DD: Racial, ethnic, socioeconomic, and access disparities in the use of preventive services among women. Prev Med 2003, 37:475-484.

3. Adams EK, Florence CS, Thorpe KE, Becker ER, Joski PJ: Preventive care: female cancer screen, 1996-2000. Am J Prev Med 2003, 25:301-307.

4. Baker D, Middleton E: Cervical screening and health inequality in England in the 1990s. J Epidemiol Community Health 2003, 57:417-423.

5. Hewitt M, Devesa SS, Breen N: Cervical cancer screening among U.S. Women: analyses of the 2000 National Health Interview Survey. Prev Med 2004, 39:270-278.

6. Sutton S, Rutherford C: Sociodemographic and attitudinal correlates of cervical screening uptake in a national sample of women in Britain. Soc Sci Med 2005, 61:2460-2465.

7. Sabates R, Feinstein $L$ : The role of education in the uptake of preventive health care: the case of cervical screening in Britain. Soc Sci Med 2006, 62:2998-3010.

8. Cabeza E, Esteva M, Pujol A, Thomas V, Sánchez-Contador C: Social disparities in breast and cervical cancer preventive practices. Eur I Cancer Prev 2007, 16:372-379.

9. Moser K, Patnick J, Beral V: Inequalities in reported use of breast and cervical screening in Great Britain: analysis of cross sectional survey data. BMJ 2009, 338:b2025

10. Garrido-Cumbrera M, Borrell C, Palència L, et al: Social class inequalities in the utilization of health care and preventive services in Spain, a country with a national health system. Int J Health Serv 2010, 40:525-542.

11. Palència L, Espelt A, Rodríguez-Sanz M, et al: Socio-economic inequalities in breast and cervical cancer screening practices in Europe: influence of the type of screening program. Int J Epidemiol 2010, 39:757-765.

12. Park MJ, Park EC, Choi KS, Jun JK, Lee HY: Sociodemographic gradients in breast and cervical cancer screening in Korea: the Korean National Cancer Screening Survey (KNCSS), 2005-2009. BMC Cancer 2011, 11:257.

13. Damiani $G$, Federico B, Basso D, et al: Socioeconomic disparities in the uptake of breast and cervical cancer screening in Italy: a cross sectional study. BMC Public Health 2012, 12:99.

14. Spadea T, Bellini S, Kunst A, Stirbu I, Costa G: The impact of interventions to improve attendance in female cancer screening among lower socioeconomic groups: a review. Prev Med 2010, 50:159-164

15. Miles A, Cockburn J, Smith RA, Wardle J: A perspective from countries using organized screening programs. Cancer 2004, 101:1201-1213.

16. Koong SL, Yen AMF, Chen THH: Efficacy and cost-effectiveness of nationwide cervical cancer screening in Taiwan. J Med Screen 2006, 13:S44-S47.

17. Chen YY, You SL, Chen CA, et al: Effectiveness of national cervical cancer screening programme in Taiwan: 12-year experiences. Br J Cancer 2009, 101:174-177.
18. Health Promotion Administration, Ministry of Health \& Welfare: Taiwan national health interview survey introduction. Accessed Sep 8, 2013 at https:/olap.hpa. gov.tw/en_US/Search/02_ListSummary.aspx?menu=100000000008\&mode=1.

19. Harper S, Lynch J: Measuring health inequalities. In Methods in Social Epidemiology. Edited by Oakes JM, Kaufman JS. San Francisco, CA: JosseyBass; 2006:134-168.

20. Regidor E: Measures of health inequalities: part 2. J Epidemio/ Community Health 2004, 58:900-903.

21. Martens PJ: The right kind of evidence-integrating, measuring, and making it count in health equity research. J Urban Health 2012, 89:925-936

22. Puddu M, Demarest S, Tafforeau J: Does a national screening programme reduce socioeconomic inequalities in mammography use? Int J Public Health 2009, 54:61-68.

23. Lee HY, Park EC, Jun JK, Hahm MI, Jung KW, Kim YJ, Han MA, Choi KS: Trends in socioeconomic disparities in organized and opportunistic gastric cancer screening in Korea (2005-2009). Cancer Epidemiol Biomarkers Prev 2010, 19:1919-1926.

24. Victora CG, Vaughan JP, Barros FC, Silva AC, Tomasi E: Explaining trends in inequality: evidence from Brazil child health studies. Lancet 2000, 356:1093-1098.

25. Chen THH, Chiu YH, Luh DL, et al: Community-based multiple screening model: design, implementation, and analysis of 42,387 participants. Cancer 2004, 100:1734-1743.

26. Chang HC, Hsiung HY, Chen SI, Yen AMF, Chen THH: Comparison of a community outreach service with opportunity screening for cervical cancer using Pap smears. J Public Health 2007, 29:165-172.

27. Mackenbach JP, Stronks K: The development of a strategy for tackling health inequalities in the Netherlands. Int J Equity Health 2004, 3:11.

doi:10.1186/1475-9276-13-4

Cite this article as: Chiou et al: Changes in the magnitude of social inequality in the uptake of cervical cancer screening in Taiwan, a country implementing a population-based organized screening program. International Journal for Equity in Health 2014 13:4.

\section{Submit your next manuscript to BioMed Central and take full advantage of:}

- Convenient online submission

- Thorough peer review

- No space constraints or color figure charges

- Immediate publication on acceptance

- Inclusion in PubMed, CAS, Scopus and Google Scholar

- Research which is freely available for redistribution 